\title{
A SHORT NOTE ON OVERALL RISK MANAGEMENT IN AN INSURANCE CONCERN
}

\author{
KARL BORCH
}

I. At an earlier ASTIN Colloquium participants were invited to present notes on problems which they considered as important but unsolved. There was little response to this invitation, presumably because a problem, once it is well formulated, is almost solved.

In this Note I do not present any new problems. In stead I try to outline a framework which may be useful for analysing different risk problems and seeing them in their proper perspective. In my view, a framework of this kind is urgently needed to place today's actuarial work on a sound foundation.

2. In general an insurance contract will define two stochastic processes. We lose little by assuming that the processes are discrete, and describing them in the following manner:

(i) The payment process: $x_{0}, x_{1} \ldots x_{t} \ldots$, where $x_{t}$ is the amount which the company pays to settle claims in period $t$, or at time $t$.

(ii) The premium process: $p_{0}, p_{1} \ldots p_{t} \ldots$, where $p_{t}$ is the premium which the company receives in period $t$, or at time $t$.

If the contract is concluded at time $t=0$, the Principle of Equivalence requires that

$$
E\left\{\sum_{t=0}^{\infty} v^{t}\left(p_{t}-x_{t}\right)\right\}=0
$$

For the typical short-term contract with premium payable in advance (I) will reduce to

$$
p_{0}=E\{x\} .
$$

3. For a long-term insurance contract one usually requires that the inequality

$$
E\left\{\sum_{i=0}^{\tau} v^{t}\left(p_{t}-x_{t}\right)\right\} \geq 0
$$

shall hold for all $\tau$. This means that the company must never be a net creditor of its customer. 
From this requirement it follows that

$$
E\left\{\sum_{i=\tau+1}^{\infty} v^{t}\left(p_{t}-x_{t}\right)\right\} \leq 0 .
$$

If the inequality is strict, the company must have additional income if it shall be able to meet its expected commitments. It is natural to formalize this by introducing:

(iii) The investment income process: $c_{0}, c_{1} \ldots c^{t} \ldots$, where $c_{t}$ is the company's receipts from investments in period $t$.

This leads to a modified Principle of Equivalence:

or

$$
E\left\{\sum_{i=\tau}^{\infty} v^{t}\left(p_{t}+c_{t}-x_{t}\right)\right\}=0
$$

$$
E\left\{\sum_{i=\tau}^{\infty} v^{t} c_{t}\right\}=E\left\{\sum_{t=\tau}^{\infty} v^{t}\left(x_{t}-p_{t}\right)\right\}
$$

4. At this point it is convenient to switch from the "individual" to the "collective" point of view. In stead of considering the three processes as defined by a single insurance contract, we can take them as determined by the company's portfolio of investments and insurance contracts.

With this interpretation

$$
V_{\tau}=E\left\{\sum_{i=\tau}^{\infty} \eta^{t-\tau}\left(x_{t}-p_{t}\right)\right\}
$$

will be the familiar "premium reserve", i.e. the liability side of the company's balance sheet at time $\tau$.

Similarly

$$
U_{\tau}=E\left\{\sum_{i=\tau}^{\infty} v^{t-\tau} c_{t}\right\}
$$

will represent the asset side of the balance sheet.

The analogy is, however, not complete. $U$ is as a rule not computed by the actuary, but by the market, which presumably evaluates an investment by calculating something similar to the expected discounted sum of future returns. There is no particular reason to expect the market to do a better job than the actuary, but if the company should be forced to liquidate, assets will have to be sold at the evaluation of the market, no matter what their "real worth" is in the opinion of the actuary. 
5. The management of an insurance company can usually influence the development of the three stochastic processes which we have introduced. This is most obvious for the $c$-process. The investment manager can, if he wants to, reduce this to a virtually deterministic process, by placing the funds in government bonds of different maturities. The most obvious way of changing the $x$ - and $p$-processes is reinsurance. For instance, a quota reinsurance on original original terms will reduce both $x_{t}$ and $p_{t}$ in the same proportion. It is, however, clear that any decision by management with regard to the company's operations, will have some effect on the two processes. The practical problem is usually to ascertain just what these effects are.

The practical problem is both intriguing and important. It seems obvious that one must know the consequences of alternative decisions in order to run an insurance company in a rational manner. The basic problem is, however, to decide how one wants the stochastic processes to develop, i.e. how the objectives of the company should be formulated operationally. This problem has been taken up by de Finetti [3], and I have discussed it in a number of papers, i.a. [I] and [2].

6. Before we study this problem, it may be useful to discuss the restrictions which government regulations impose on the company's operations. The purpose of these regulations is to protect the public, mainly by making reasonably certain that the company is solvent, i.e. able to meet its commitments.

In the accounting sense the company is solvent at time $\tau$ if

$$
U_{\tau}-V_{\tau} \geq 0
$$

The solvency requirement is, with few exceptions, absolute. If the inequality is not satisfied, the company will have to go into liquidation, even if there is a good chance that it may regain solvency later. This means that one will want the inequality to hold with a good margin, for instance by requiring that

$$
U_{\tau} \geq(\mathrm{I}+\lambda) V_{\tau}
$$

where $\lambda>0$. The purpose of maintaining a safety margin of this kind is obviously to avoid, or reduce the probability of insolvency in the future. This objective may be stated directly by requiring that 


$$
\operatorname{Pr}\left\{\min _{t \varepsilon T}\left(U_{\tau+t}-V_{\tau+t}\right) \geq 0\right\} \geq \alpha_{T}
$$

Here the set $T$ may consist of the non-negative part of the real line, the positive integers, or some other suitable set. $\alpha_{T}$ is the probability that the company shall be solvent for all $t$ in $T$, and should presumably be fairly close to unity.

7. In principle the government could specify a set $T$ and a corresponding probability $\alpha_{T}$, and leave the company to find its own. way to satisfy the condition (4). This is not done in practice, presumably because the government does not know how high safety requirements can or should be set. In stead of one general regulation, governments usually have issued a series of detailed regulations, about investment, evaluation methods, premium rates, etc.. Some of these regulations may have a poor theoretical foundation, but their intended effect is clearly to increase $\alpha_{T}$, at least for some sets $T$.

One can reasonably ask if such government regulations really are necessary, since most insurance companies will argue that they maintain a higher safety standard than the minimum required by the government. This brings us right back to the question as to what objectives an insurance company pursues.

8. De Finetti suggested that the objective of an insurance company may be to maximize the expected discounted sum of the dividends it will pay during its lifetime. This sounds quite acceptable, and the suggestion is in good accordance with modern economic theory. The suggestion has the additional merit that it leads to very interesting mathematical problems. The snag is that with this objective, the company will never reinsure any part of its portfolio, except on a reciprocal basis. Since we observe the companies indeed reinsure, they must pursue objectives, different from that suggested by de Finetti.

\section{REFERENCES}

[I] BoRCH, K. "The Theory of Risk" (with discussion), Journal of the Royal Statistical Society, Series B, Vol 29 (r967) pp 423-467

[2] Borch, K "The Rescue of an Insurance Company after Ruin", The ASTIN Bulletin, Vol 5 (I969) pp. 280-292.

[3] Finetti, B DE "Su una Impostazione Alternativa della Theoria Colletiva del Rischio" Transactions of the XV International Congress of Actuaries I957, Vol II, pp 433-443 